\title{
Breast cancer awareness among female school teachers in Makkah region, Saudi Arabia- A cross-sectional study
}

\author{
Alshareef $\mathrm{B}^{1}$, Yaseen $\mathrm{W}^{2 *}$, Jawa $\mathrm{W}^{2}$, Barnawi $\mathrm{Y}^{2}$, Alqtham $\mathrm{H}^{2}$, Bukhari $\mathrm{W}^{2}$, Alshehri $\mathrm{W}^{2}$ and Alqumaili $\mathrm{O}^{2}$ \\ Department of Surgery, Umm Al-Qura University, Mecca, Saudi Arabia
}

\begin{abstract}
Introduction: Breast cancer $(\mathrm{BC})$ is the most frequent malignancy of women and second leading cause of cancer related death worldwide. In Saudi Arabia, is the ninth cause of death. Few studies have been conducted to address BC awareness in KSA in general and to our knowledge, this is the first to be conducted in Makkah region.
\end{abstract}

Aim: To assess the level of awareness knowledge, attitude of Saudi female teachers towards BC in primary, intermediate and secondary schools in Makkah region.

Method and materials: The study proposal was approved by the Research Ethical Committee in faculty of medicine, Umm Al-Qura University. A self-administered questionnaire on $\mathrm{BC}$ was designed and tested. Questionnaire consisted of 23 items covered four domains (awareness about the aetiology, knowledge about $\mathrm{BC}$ risk factors, symptoms, knowledge about diagnosis and treatment \& attitude toward screening). A sample of 400 female school teachers working in primary, intermediate and secondary schools was selected by multistage random sampling. Forty schools in Makkah were selected randomly, and a convenient sample of 10 teachers from each school was randomly selected as well. Proper permission was obtained from the authorities. The collected data statistically analyzed using SPSS version 21.

Results: The results showed significant knowledge \& attitude about $\mathrm{BC}$ among the female teachers differed significantly by their age and marital status. Those aged 46-55 $(\mathrm{F}=8.5, p>0.00)$ and those who are married $(\mathrm{F}=2.7, p>0.04)$ had more knowledge about $\mathrm{BC}$ than others. The majority of respondents had limited level of knowledge and understanding of $\mathrm{BC}$ symptoms. However, it also showed that the teachers are very enthusiastic to learn about $\mathrm{BC}$, and its prevention. Most participants reported that they did not perform any breast exam before (40/\%).

Conclusions and recommendation: This study indicated that Saudi female teachers' level of knowledge of BC is inadequate. This might be an obstacle to screening program. Public-awareness interventions are needed in order to overcome an ever-increasing burden of this disease among Saudi females and introducing and develop an effective health education program in female schools in KSA is recommended.

\section{Introduction}

Brest Cancer (BC) as a multifactorial disease is the most common cancers and the second leading cause of deaths among women worldwide [1]. The incidence of $\mathrm{BC}$ is rising more rapidly in the population group that use to enjoy low incidence of the disease and it reduces the life expectancy of the population at risk especially those between 31 and 50 [2].

Global statistics show that the annual morbidity and mortality of $\mathrm{BC}$ are increasing, in which over 1.15 million women worldwide (representing 10 percent of all diagnosed cancers and 23 percent of cancers diagnosed in women) are diagnosed with $\mathrm{BC}$ each year and more than 502,000 of them die from this disease (more than $1.6 \%$ of all female mortality worldwide) [3].

Women in the Middle East face a significant risk of high mortality rate from $\mathrm{BC}$ due to the delay in the diagnosis and the advanced stages of the disease at the time of diagnosis. In kingdom of Saudi Arabia; $\mathrm{BC}$ usually diagnosed at late stage and more frequently in young premenopausal women under age of 45 years in comparison to western countries [4].

The aetiology of the majority of BCs is unknown with only about $25 \%$ to $40 \%$ of them may be attributed to well known risk factors [5].

Awareness of BC risk factors (gender, age, family or personal history, racial factor, radiation exposure, breast changes, early menarche, late menopause, prolonged null parity, overweight, diet, alcohol consumption, tobacco smoking, excessive estrogenic exposure, oral contraceptive use, stress and anxiety.) and perception of personal risk are important factors for motivation, prevention, and/ or early detection of the disease [6-8], knowledge about screening methods and warning signs and of the disease plays an important and effective role towards developing and employing screening programs in a community, which can effectively improve the chances of early detection of $\mathrm{BC}$ in early stages witch result in improvement in survival rate and quality of life [9].

However, late diagnosis of $\mathrm{BC}$ is mainly due to lack of awareness in the population and barriers to access to health services (WHO, 2012) [10].

Early detection of $\mathrm{BC}$ can be achieved through: Implementing effective screening programs and annual mammography in targeted population; and improve public awareness about signs and symptom of $\mathrm{BC}$ and encouragement of females to take a prompt action [10-13].

${ }^{\star}$ Correspondence to: Yaseen Waed, Department of Surgery, Umm Al-Qura University, Mecca, Saudi Arabia, E-mail: waedyaseen@hotmail.com

Key words: breast cancer, Saudi Arabia, screening, awareness, knowledge, school teachers

Received: October 12, 2018; Accepted: December 12, 2018; Published: December 20, 2018 
In Saudi Arabia, unfortunately we don't have any national screening program; however, there are several local / regional programs / activities such as: the public awareness of $\mathrm{BC}$, through lectures, in a major hospital in Riyadh [14], a year-round, well-designed public awareness program, and the first organized population-based screening mammography program in Alqassim region [15].

There is very little information exists on the perception and believes of females in Saudi Arabia about BC and its control; and it is wellknown that to improve cancer control, it is important to understand what they know about the disease and its screening, early detection and treatment [16].

In KSA, studies related to knowledge, attitudes, and practices around BC are scarce. Milaat et al. [17] found a very low level of knowledge of $\mathrm{BC}$ and its associated risk factors among female highschool students. However, an older female population from Riyadh was found to be more knowledgeable about BC. Among 864 women aged 20-50 years old and living in Riyadh, $82 \%$ knew about breast selfexamination, and $61 \%$ knew about mammography. However, only $41.2 \%$ had performed breast self-examination, and only $18.2 \%$ had ever had a mammogram [8]. In Al Hassa governorate, a population-based study found even lower rates of mammography, 5.1\% among 1,315 women aged 18-65 years old [9]. Another study of teachers in their thirties also showed low levels of breast-cancer-related knowledge, with only $32.4 \%$ being aware of breast self-examination [10]. Whether Saudi women know about BC screening and whether those above 50 years are being screened for $\mathrm{BC}$ at least once every two years is unknown. We conducted a regional survey to investigate knowledge and practices of BC screening among school teachers in order to asses stress the need $\mathrm{BC}$ and cancer awareness national health programs.

Several studies have shown inadequate levels of knowledge towards risk factors awareness and cancer screening like clinical breast examination and mammography, even among educated women $[18,19]$.

In Saudi Arabia, few studies have been carried out to assess awareness towards risk factors of $\mathrm{BC}$ with some methodological limitations [11,19]. While none exist assessing distribution of various risk factors implicated in BC as well as screening behaviour. Consequently, the objective of this study was to assess level and determinants of knowledge about, risk factors behaviour and utilization of screening methods used for BC.

Cost and availability of health insurance have been found to act as barriers to BC screening in the U.S. and other parts of the world, but not in Saudi Arabia where mammography is usually either free or covered by insurance $[17,19]$.

We aim in this study to assess knowledge, awareness, attitude and practice of Saudi female towards BC and screening for BC. We picked school teachers as our sample because they constitute a large number in the population and the result of the study, we believe, can be applied to the whole population of Saudi Arabia.

Also, school teachers are classified as well-educated sector in the country and it is expected that they are very well aware and oriented about BC.

Finally, we couldn't find any similar study done in Makkah region and we hope by this study that we can attract some attention to develop awareness and screening programs for $\mathrm{BC}$ here.

\section{Methods and materials}

\section{Study Design}

Cross-sectional survey in the Makkah city.

\section{Study population and sample size}

A total sample of 400 school teachers working in primary, intermediate and secondary schools was selected by multistage random sampling. Forty schools in the city of Makkah city were selected randomly, and a convenient sample of 10 teachers from each school were randomly selected as well. Sample size was determined using sample size determination tables as ministry of education website total number of teachers is 12905 sample size is 365 . However, considering $10 \%$ non-response rate the final sample size is 400 .

\section{Instruments}

A questioner was developed based on a comprehensive review of literature to include questions on women's awareness level about different aspects of BC. The original questionnaires were in English for which translation into Arabic with back translation to English was done to preserve the original construct. Content validity was reviewed by two experts in the field. Twenty-three questions covering the important aspects of $\mathrm{BC}$ that the public should know including: risk factors, signs, screening, treatment methods and screening centers in Makkah and the source of each information. Questions assessing knowledge score was given a value of one if correct and zero if incorrect. Total knowledge score was 37 .

Data collectors were recruited and trained for two days. In the training session the data collectors were oriented about the subject itself, we give them a workshop to explain objectives of the study and data collection process. All collected data were reviewed by the supervisors and principle investigators.

Initially, we did a pilot study on 10 school teachers to ensure quality, clarity and completeness of data.

\section{Statistical analysis}

Data were analyzed using SPSS software, version 21. Scores of knowledge items were summed to obtain the mean total knowledge score on BC total scores were found to be normally distributed. Descriptive tests (frequency, mean, standard deviation (SD) and percentages) were done to characterize different variables. Parametric test (T-test and ANOVA test) were applied to compare knowledge across the socio-demographic variables. Multiple linear regression analysis was performed to obtain the significant predictors of $\mathrm{BC}$ knowledge. The level of significance was set below $5 \%(p<0.05)$.

\section{Ethical consideration}

Participants were informed about the study nature. Written consent was obtained. All information obtained from participants were anonymous. Approval from Research Ethical Committee in the faculty of medicine was obtained, Umm Al-Qura University, and the study was conducted after approval.

\section{Results}

The response rate was $100 \%$ as all participants responded to the questionnaire; the majority of the respondents were between 36 and 45 years old (49\%), married (70\%) and hold a bachelor's degree (77\%). Seventy eight percent of them didn't have a family history of BC and $81 \%$ haven't had any breast disease before (Table 1 ). 
Table1. Socio-demographic characteristics of the respondents $(\mathrm{n}=400)$

\begin{tabular}{|c|c|c|}
\hline Characteristic & $\mathbf{N}$ & $\%$ \\
\hline \multicolumn{3}{|l|}{ Age } \\
\hline $25-35$ & 145 & 36.3 \\
\hline $36-45$ & 197 & 49.3 \\
\hline $46-55$ & 58 & 14.5 \\
\hline \multicolumn{3}{|l|}{ Marital status } \\
\hline Single & 71 & 17.8 \\
\hline Married & 282 & 70.5 \\
\hline Divorced & 32 & 8 \\
\hline Widowed & 15 & 3.8 \\
\hline \multicolumn{3}{|l|}{ Educational level } \\
\hline Diploma & 66 & 16.5 \\
\hline Bachelor & 311 & 77.8 \\
\hline Master & 15 & 3.8 \\
\hline Doctorate & 2 & .5 \\
\hline Others & 6 & 1.5 \\
\hline \multicolumn{3}{|l|}{ Family history of breast cancer } \\
\hline Yes & 63 & 15.8 \\
\hline No & 314 & 78.5 \\
\hline I don't know & 23 & 5.8 \\
\hline \multicolumn{3}{|l|}{ *Who had breast cancer in family } \\
\hline Mother & 21 & 33.3 \\
\hline Sister & 5 & 7.9 \\
\hline Ant & 14 & 22.2 \\
\hline Grandmother & 5 & 7.9 \\
\hline Others & 18 & 28.6 \\
\hline \multicolumn{3}{|l|}{ Had Breast Disease } \\
\hline No & 227 & 81.5 \\
\hline breast inflammation & 15 & 3.7 \\
\hline breast ulcer & 3 & 0.7 \\
\hline breast tumor & 4 & 1 \\
\hline nipple secretions & 23 & 5.7 \\
\hline breast lump & 27 & 6.7 \\
\hline other breast problem & 2 & 0.5 \\
\hline Have you ever had a mammogram ?(yes) & 51 & 12.8 \\
\hline \multicolumn{3}{|l|}{ If yes, why? } \\
\hline For Screening & 36 & $70.59 *$ \\
\hline For Diagnosis & 15 & $29.41^{*}$ \\
\hline have you ever done breast self-examination? (yes) & 169 & 42.3 \\
\hline \multicolumn{3}{|l|}{ if no why? } \\
\hline I did not know it excited & 37 & 15.7 \\
\hline I don't know how to do it & 120 & 50.8 \\
\hline I don't think it's important & 14 & 5.9 \\
\hline I don't think I need it & 65 & 27.5 \\
\hline
\end{tabular}

*For participants' who answered Yes $(\mathrm{n}=63)$

Table 2 illustrates respondents' knowledge about risk factors and warning signs. Alcohol drink (82\%) was the most identified risk factor, followed by family history (69\%) and long term oral contraceptive pills use (66\%). Increase maternal age at first pregnancy $(0.9 \%)$ was the least identified risk factor, followed by late menopause (hormonal therapy exposure) (3\%) and early menarche (5\%). Majority of respondents identified lump under armpit (75\%) as a BC warning sign followed by painless breast lump (65\%) and bleeding or discharge from the nipple (52\%). Wight loss (22\%) and nipple pain (35\%) were the least identified warning signs of $\mathrm{BC}$.

Respondents' mean scores of their overall knowledge about BC based on some demographical characteristics. It is found that overall mean score for the participants' knowledge levels about BC is $15.6 \pm$ 4.19 , most of participants' (67\%) had a weak score knowledge, followed by average knowledge score of (24\%) lowest percentage of participants' (6\%) had a good knowledge score.

School teacher's knowledge about $\mathrm{BC}$ differed significantly by their age and marital status, as those aged $46-55(\mathrm{~F}=8.5, p>0.00)$ and those who are married $(\mathrm{F}=2.7, p>0.04)$ had more knowledge about $\mathrm{BC}$ than others (Tables 3 and 4 ).

Univariate linear regression analysis was done to the age, Marital Status, education level, those with family history of $\mathrm{BC}$ and those who had breast disease. Multi-collinearity was checked, and the analysis showed no intercorrelation among the independent variables. Only age was statistically significant $(P<0.05)$ (Table 5$)$.

Forty five percent of participants' knew about BC Screening centers in Makkah city, $93.3 \%$ of respondents think that early BC screening is important and $92.3 \%$ stated that they would go to see a doctor only if

Table 2. Respondents knowledge about risk factors and warning signs of breast cancer

\begin{tabular}{|l|c|c|}
\hline \multirow{2}{*}{ Item } & \multicolumn{2}{|c|}{ True } \\
\cline { 2 - 3 } Risk Factors & $n$ & $\%$ \\
\hline Family History & 278 & $69.5 \%$ \\
\hline Early menarche & 23 & $5.8 \%$ \\
\hline Old age of first pregnancy & 25 & $0.9 \%$ \\
\hline Early menopause & 101 & $25.3 \%$ \\
\hline Aging & 104 & $26.0 \%$ \\
\hline Increase maternal age at first pregnancy & 25 & $6.3 \%$ \\
\hline Early menopause & 101 & $3.7 \%$ \\
\hline Number of pregnancies' & 84 & $21.0 \%$ \\
\hline Infertility & 68 & $17.0 \%$ \\
\hline Staying Single & 46 & $11.5 \%$ \\
\hline Obesity & 113 & $28.3 \%$ \\
\hline Fatty foods & 134 & $33.5 \%$ \\
\hline OCP use & 265 & $66.3 \%$ \\
\hline Increased Stress Levels & 275 & $68.8 \%$ \\
\hline X-ray Exposure & 315 & $78.8 \%$ \\
\hline Smoking & 251 & $62.8 \%$ \\
\hline Alcohol drink & 331 & $82.8 \%$ \\
\hline Worming Sings & & \\
\hline Painless Breast Lump & 168 & $65.4 \%$ \\
\hline Changes in the size of breast or nipple & 261 & $48.1 \%$ \\
\hline Changes in the shape of breast or nipple & 203 & $50.9 \%$ \\
\hline Bleeding or discharge from the nipple & 210 & $52.6 \%$ \\
\hline Pulling of the nipple & $172.1 \%$ \\
\hline nipple pain & 300 & $35.6 \%$ \\
\hline Wight loss & & $22.1 \%$ \\
\hline Redness of the breast skin & & $72.9 \%$ \\
\hline Lump under armpit & & \\
\hline & & \\
\hline
\end{tabular}

Lump under armpit

Table 3. Participants' Knowledge Score Toward BC

\begin{tabular}{|c|c|c|c|c|c|c|}
\hline & \multicolumn{2}{|c|}{$\begin{array}{c}\text { Disease knowledge } \\
\text { score }=\mathbf{3 0}\end{array}$} & \multicolumn{2}{|c|}{$\begin{array}{l}\text { Screening knowledge } \\
\text { score }=7\end{array}$} & \multicolumn{2}{|c|}{$\begin{array}{c}\text { Overall knowledge } \\
\text { score }=\mathbf{3 7}\end{array}$} \\
\hline & $\mathrm{N}$ & $\%$ & $\mathrm{~N}$ & $\%$ & $\mathrm{~N}$ & $\%$ \\
\hline Weak* & 246 & 61.5 & 202 & 50.5 & 271 & 67.75 \\
\hline Average* & 99 & 24.7 & 182 & 45.5 & 96 & 24 \\
\hline Good* & 6 & 1.5 & 6 & 1.5 & 6 & 1.5 \\
\hline Range & \multicolumn{2}{|c|}{$3-24$} & \multicolumn{2}{|c|}{$3-6$} & \multicolumn{2}{|c|}{$6-29$} \\
\hline Mean \pm SD & \multicolumn{2}{|c|}{$12.27 \pm 3.93$} & \multicolumn{2}{|c|}{$3,33 \pm 1.11$} & \multicolumn{2}{|c|}{$15.6 \pm 4.19$} \\
\hline \multicolumn{7}{|l|}{ Chi-square } \\
\hline $\mathrm{X}^{2}$ & \multicolumn{2}{|c|}{286.8} & \multicolumn{2}{|c|}{197.60} & \multicolumn{2}{|c|}{205.110} \\
\hline$P$ & \multicolumn{2}{|c|}{$<0.001$} & \multicolumn{2}{|c|}{$<0.001$} & \multicolumn{2}{|c|}{$<0.001$} \\
\hline
\end{tabular}

*Weak (score 49-25\%), Average (score 50-74\%), Good ( score $\leq 75 \%$. 
Table 4. Differences in Respondents Breast Cancer knowledge by Demographic Variables

\begin{tabular}{|c|c|c|c|c|}
\hline Characteristic & Mean & SD & $\mathbf{F}$ & P-Value \\
\hline \multicolumn{5}{|l|}{ Age } \\
\hline $25-35$ & 17.62 & 3.608 & \multirow{3}{*}{8.516} & \multirow{3}{*}{.000} \\
\hline $36-45$ & 18.81 & 3.902 & & \\
\hline $46-55$ & 19.98 & 4.470 & & \\
\hline \multicolumn{5}{|l|}{ Marital status } \\
\hline Single & 17.46 & 3.660 & \multirow{4}{*}{2.780} & \multirow{4}{*}{.041} \\
\hline Married & 18.89 & 4.044 & & \\
\hline Divorced & 17.94 & 3.991 & & \\
\hline Widowed & 18.47 & 2.669 & & \\
\hline \multicolumn{5}{|c|}{ Educational level } \\
\hline Diploma & 19.05 & 4.145 & \multirow{5}{*}{.721} & \multirow{5}{*}{.578} \\
\hline Bachelor & 18.42 & 3.938 & & \\
\hline Master & 18.40 & 3.699 & & \\
\hline Doctorate & 22.00 & 7.071 & & \\
\hline Others & 18.67 & 2.944 & & \\
\hline \multicolumn{5}{|c|}{ Family history of breast cancer } \\
\hline Yes & 18.73 & 4.064 & \multirow{3}{*}{1.545} & \multirow{3}{*}{.215} \\
\hline No & 17.87 & 3.348 & & \\
\hline I don't know & 17.91 & 3.942 & & \\
\hline \multicolumn{5}{|c|}{ Had breast disease } \\
\hline Yes & 18.48 & 3.969 & \multirow{2}{*}{$-.162-*$} & \multirow{2}{*}{-.083-* } \\
\hline No & 18.56 & 3.963 & & \\
\hline \multicolumn{5}{|c|}{ Practice breast self-examination } \\
\hline Yes & 19.07 & 4.121 & \multirow{2}{*}{$2.32 *$} & \multirow{2}{*}{$.021 *$} \\
\hline No & 18.13 & 3.756 & & \\
\hline \multicolumn{5}{|c|}{ Had mammography } \\
\hline Yes & 19.65 & 5.047 & \multirow{2}{*}{$2.193^{*}$} & \multirow{2}{*}{$.085^{*}$} \\
\hline No & 18.36 & 3.726 & & \\
\hline
\end{tabular}

*T-statistic and p-value are based on the results of t-test

Table 5. Predictors of breast cancer knowledge by univariate linear regression $(n=400)$

\begin{tabular}{|c|c|c|c|c|c|c|}
\hline & \multirow{2}{*}{ B } & \multirow{2}{*}{ SE } & \multirow{2}{*}{ Beta } & \multirow{2}{*}{$P$ value } & \multicolumn{2}{|c|}{$95 \%$ CI } \\
\hline & & & & & Lower & Upper \\
\hline Age & 1.182 & .286 & .203 & .000 & .620 & 1.745 \\
\hline Marital Status & .337 & .310 & .054 & .277 & $-.273-$ & .947 \\
\hline Educational Level & $-.136-$ & .334 & $-.020-$ & .685 & $-.792-$ & .521 \\
\hline Family History & -.572 & .353 & $-.081-$ & .106 & $-1.26-$ & .122 \\
\hline Had Breast Disease & $-.083-$ & .513 & $-.008-$ & .871 & $-1.09-$ & .926 \\
\hline
\end{tabular}

they had breast problem and over half of the participants would agree to participate in a $\mathrm{BC}$ screening program.

Fifty-one participant had mammography and only 31 out of them were for screening. Out of all participants $57 \%$ thought that BC treatment depends on the stage (Table 6).

\section{Discussion}

In Saudi Arabia, BC is the most common cancer among females. It usually presents at advanced stages and is considered the leading cause of cancer mortality in women (14\% of female cancer deaths). Since it is known that education and awareness lead to better screening and subsequently early detection which contribute to better treatment and prognosis, we designed this study to investigate the level of BC awareness among Saudi females teachers in Makkah, and as we can see that only $3.8 \%$ know what mammogram is and only $8 \%$ know that it should be started at the age of 50 , these results unfortunately reflects poor knowledge of the study group and when we looked at the literature there was no similar study asked the same question. When it comes to the treatment options, we found that also there is relatively poor knowledge about treatment choices of breast cancer (57\% know that it depends on the stage) (Table 7).
Our findings show that overall mean score for the participants' information levels about breast cancer is $15.6 \pm 4.19$, most of participants' (67\%) had a weak score knowledge of $49-25 \%$, followed by average knowledge score of $50-74 \%$ (24\%) lowest percentage of participants' (6\%) had a good knowledge score of $\geq 75 \%$. Regarding the screening methods $50 \%$ of our sample had a weak knowledge and $1.5 \%$ had a good score.

Also, this finding support previous study by Alam et al. [11], she reported smoking, hormone replacement therapy and exposure to excess radiation as common BC risk factors noted by women in Riyadh.

Regarding women's' awareness of $\mathrm{BC}$ warning signs; painless breast lump was the most frequently identified symptom (65\%) followed by bleeding or nipple discharge (52\%) and change in the shape of breast or nipple (50\%). Knowledge of other warning signs were limited as only few females knew that weight loss (22\%) and nipple pain (35\%) are warning sign of BC. Radi et al. [20] reported similar findings in their study.

This finding is in agreement with what has been reported by Parisa Parsa et al. [21], in their study they reported that the majority of participants had low level of knowledge (63\%).

When we compared the demographic variables of our population, we noted that marital status and age affected significantly awareness level; as older married females learn more about the disease and were more aware about screening methods. However, we found that educational level didn't affect awareness about BC as more educated females didn't necessarily know more about the disease or its screening.

The results were consistent with the literature as published by Dandash et al. [16] \& Amin TT et al. [18] but on the other hand these

Table 6. Participants' Attitude Toward Screening Programs

\section{Question}

Do you know any breast cancer screening center in Makkah?

Do you think early breast cancer screening is important?

Would you agree to participate in a Breast Cancer screening Program If offered?

if you or a family member had any breast problem would you go to the doctor?

have you ever had a breast cancer examination by a doctor?

\begin{tabular}{|c|c|}
\hline $\mathbf{n}$ & $\mathbf{\%}$ \\
\hline 181 & 45.3 \\
\hline 385 & 96.3 \\
\hline 237 & 59.3 \\
\hline 369 & 92.3 \\
\hline 107 & 26.8 \\
\hline
\end{tabular}

Table 7. Participants' Knowledge About Breast Cancer Screening and Treatment

\begin{tabular}{|l|c|c|}
\hline Question & $\mathbf{n}^{*}$ & $\mathbf{\%}$ \\
\hline $\begin{array}{l}\text { What percentage do you think the risk of breast cancer in } \\
\text { women? (<25\%) }\end{array}$ & 155 & 38.8 \\
\hline What is mammogram? (breast x-ray) & 33 & 3.8 \\
\hline How often should mammogram be done? (annually) & 93 & 23.3 \\
\hline At what age do you think mammogram screening should start? (50) & 32 & 8 \\
\hline Have you ever had a mammogram? (yes) & 51 & 12.8 \\
\hline If yes, why? & & \\
\hline For Screening & 36 & $70.59 *$ \\
\hline For Diagnosis & 15 & $29.41^{*}$ \\
\hline have you ever done breast self-examination? (yes) & 169 & 42.3 \\
\hline if no why? & & \\
\hline I did not know it excited & 37 & 15.7 \\
\hline I don't know how to do it & 120 & 50.8 \\
\hline I don't think it's important & 14 & 5.9 \\
\hline I don't think I need it & 65 & 27.5 \\
\hline What is the treatment of breast cancer? & 69 & 17.3 \\
\hline Chemotherapy and radiotherapy & 16 & 4 \\
\hline Hormonal therapy & 84 & 21 \\
\hline Surgery or removal of the whole breast & 231 & 57.7 \\
\hline It depends the stage & & \\
\hline
\end{tabular}


studies showed significant effect of education as awareness level un like our study which showed no difference, we think that discrepancy is related to this study group itself.

In the last part of the study we measured the response to screening programs in the literature Radi et al. [20], reported better knowledge and in Jeddah city which is not far from makkah and have almost similar population demography.

We think this difference mainly due to the society and awareness campaigning which is usually in Jeddah city.

\section{Conclusions}

Brest Cancer is the most common cancers and the second leading cause of deaths among women worldwide but unfortunately there is huge defect in the awareness among females in Makkah and in the country in general.

\section{Recommendation}

In order to decrease mortality and morbidity of $\mathrm{BC}$ we need better awareness which is done only through awareness and screening programs.

\section{References}

1. Montazeri A, Vahdaninia M, Harirchi I, Harirchi AM, Sajadian A, et al., (2008) Breas cancer in Iran: need for greater women awareness of warning signs and effective screening methods. Asia Pac Fam Med 7: 6. [Crossref]

2. Adebamowo CA, Adekunle OO (1999) Case-controlled study of the epidemiological risk factors for breast cancer in Nigeria. Br J Surg 86: 665-668. [Crossref]

3. Ferlay J, Bray F, Pisani P, Parkin DM, globocan 2002: Cancer incidence, mortality and prevalence worldwide, iarc cancer base no. 5, version 2.0, iarc press, lyon, france, 2004, valero-malaria in colombia, 2007.

4. Alharbi NA, Alshammari MS, Almutairi BM, Makboul G, El-shazly MK (2012) Knowledge, awareness, and practices concerning BC among kuwaiti female school teachers. Ajm 48: 75-82.

5. American cancer society, BC facts and figures 2009-2010, american cancer society, Atlanta, GA, USA, 2009.

6. Bassey RB, Irurhe N, Olowoyeye MA, Adeyomoye AA, Onajole AT (2010) Knowledge, attitude and practice of breast self-examination among nursing students in lagos university teaching hospital. Academic journal of cancer research 3: 11-15.
7. Irurhe NK, Olowoyeye OA, Arogundade RA, Bassey RB, Onajole AT (2011) Knowledge, attitude and practice of breast self-examination among female medical students in university of Lagos. The internet journal of health 12: 1-6.

8. Rojas K, Stuckey A (2016) Breast Cancer Epidemiology and Risk Factors. Clin Obstet Gynecol 59: 651-672. [Crossref]

9. Elmore JG, Armstrong K, Lehman CD, Fletcher SW (2005) Screening for breast cancer. JAMA 293: 1245-1256. [Crossref]

10. Abulkhair OA, Al Tahan FM, Young SE, Musaad SM, Jazieh AR (2010) The first national public breast cancer screening program in saudi arabia. Ann saudi med 30: 350-357. [Crossref]

11. Alam AA (2006) Knowledge of breast cancer and its risk and protective factors among women in Riyadh. Ann Saudi Med 26: 272-277. [Crossref]

12. Burgess CC, Linsell L, Kapari M, Omar L, Michell M, et al (2009). Promoting early presentation of $\mathrm{BC}$ by older women: a preliminary evaluation of a one-to-one health professional-delivered intervention. J psychosomatic res 67: 377-387. [Crossref]

13. Forbes LJ, Linsell L, Atkins L, Burgess C, Tucker L, et al (2011) Promoting early presentation intervention increases $\mathrm{BC}$ awareness in older women after 2 years: a randomised controlled trial. Br j cancer 105: 18-21. [Crossref]

14. Abulkhair OA, Al Tahan FM, Young SE, Musaad SM, Jazieh AR (2010) The first national public breast cancer screening program in Saudi Arabia. Ann Saudi Med 30: 350-357. [Crossref]

15. Ravichandran K, Al-Hamdan NA, Mohamed G (2011) Knowledge, attitude, and behaviour among Saudis toward cancer preventive practice. J Family Community Med 18: 135-142. [Crossref]

16. Dandash KF, Al-Mohaimeed A (2007) Knowledge, Attitudes, and Practices Surrounding Breast Cancer and Screening in Female Teachers of Buraidah, Saudi Arabia. Int J Health Sci 1: 61-71. [Crossref]

17. Milaat WA (2000) Knowledge of secondary-school female students on breast cancer and breast selfexamination in Jeddah, Saudi Arabia. East Mediterr Health J 6: 338344. [Crossref]

18. Amin TT, Al Mulhim ARS, Al Meqihwi A (2009) Breast cancer knowledge, risk factors and screening among adult Saudi women in a primary health care setting. Asian Pac J Cancer Prev 10: 133-138. [Crossref]

19. Bener A, El Ayoubi HR, Moore MA, Basha B, Joseph S, et al. (2009) Do we need to maximise the breast cancer screening awareness? Experience with an Endogamous Society with high fertility. Asian Pac J Cancer Prev 10: 599-604. [Crossref]

20. Radi SM (2013) Breast Cancer awareness among Saudi females in Jeddah. Asian Pac J Cancer Prev 14: 4307-12. [Crossref]

21. Parsa P, Kandiah M, Mohd Zulkefli NA, Rahman HA (2008) Knowledge and behavior regarding breast cancer screening among female teachers in Selangor, Malaysia. Asian Pac J Cancer Prev 9: 221-227. [Crossref]

Copyright: $\odot 2018$ Alshareef B. This is an open-access article distributed under the terms of the Creative Commons Attribution License, which permits unrestricted use, distribution, and reproduction in any medium, provided the original author and source are credited. 